8-27-1983

\title{
Spinal disease presenting as acute abdominal pain
}

M J. Torrens

Rashid Jooma

Follow this and additional works at: https://ecommons.aku.edu/pakistan_fhs_mc_surg_neurosurg

Part of the Neurology Commons, Orthopedics Commons, and the Surgery Commons 
the youngest, a 50 year old woman with a complete D11 paraplegia of several days' duration, had only a minimal and transient improvement in her neurological state and died shortly thereafter. Early and accurate diagnosis and the appropriate surgical approach are essential.

B M FLOOD

P DEACON R A Dickson

Department of Orthopaedic Surgery,

Clinical Sciences Building,

Leeds LS9 7 TF

' Allen EH, Cosgrave D, Mullard FJC. The radiological changes in infections of the spine and their
diagnostic value. Clin Radiol $1978 ; 29: 31-40$.

2 Ito H, Tsuchiya J, Asami G. A new radical operation
for Pott's disease. I Bone foint Surg 1934;16:499.

for Pott's disease. 7 Bone foint Surg $1934 ; \mathbf{1 6}: 499$.
'Hodgson AR, Stock FE, Fang HSY. Anterior spinal fusion - the operative approach and pathological
findings in 412 patients with Pott's disease of the findings in 412 patients with Pott's disease of the

' Lonstein JE, Winter RB, Moe JB, Bradford DS, Chou SN, Pinto WC. Neurologic defects secondary to spinal deformity. Spine 1980;5:331-55.

Breig A. Biomechanics of the spinal cord in kyphosis and kyphoscoliosis. Acta Neurol Scand 1964;40:196.

Stagnara P, Boullint G, Fauchet R, Du Peloux J.

Considerations sur le traitement orthopedique des paraplegies cypho-scoliotiques. Rev Neurol (Paris) 1965;112:122-7.

- Risko T, Novoszel T. Angaben uber die Kontraindikation der Laminotie bei Patienten mit Wirbelsaulendeformitat. Z Orthop 1965;99:425-30.

Curtis BH, Butterfield WL, Saunders FP. Neurofibromatosis of the spine

Surg $[A m] 1966 ; 48: 1023$.
1" Cattell H, Clark G. Cervical kyphosis and instability following multiple laminectomies in children. $\mathcal{F}$ Bone foint Surg $[$ Am] 1967;49:713-20.

Leathermann KD, Dickson RAD. Two stage corrective surgery for congenital deformities of the spine. $\mathcal{F}$ Bone foint Surg [Br] 1979;61:324-8.

** We sent a copy of this letter to the authors, who reply below.-ED, $B M \mathcal{}$.

SIR,-Mr Flood and others are correct in what they write, but their discussion of spinal infection covers only part of the clinical problem. They have assumed that "spinal infection" means osteomyelitis of the spine, whereas the commonest infective cause of paraplegia is extradural spinal abscess, as in the case we reported. In such patients there are usually no changes on the plain radiographs, no osteomyelitis, and the abscess is diffusely distributed through the epidural space. Laminectomy and drainage are the correct treatment for extradural spinal abscess except, rarely, when it is secondary to osteomyelitis.

\section{J TORRENS}

R JOOMA

Department of Neurosurgery,

\section{Frenchay Hospital,}

\section{Protective effect of vitamin $E$ against intraventricular haemorrhage in premature babies}

SIR,-Dr Malcolm Chiswick and others (9 July, p 81) have added another substance to the rapidly growing list of agents reputed to reduce the incidence of periventricular haemorrhage. ${ }^{1-3}$ The data they present must be challenged, as must the relevance of their findings. The hypothesis they put forward hinges on vitamin $\mathrm{E}$ reducing the risk of extension of subependymal haemorrhage into the ventricles, and they claim to have shown that it does so. The assumption is made that ultrasound distinguishes pure subependymal haemorrhage from subependymal haemorrhage that has ruptured into the lateral ventricles, a contention I believe to be unjustified. Haemor- rhage within the subependymal layer and thrombus within the ventricle are certainly echogenic, but there is no reliable evidence that liquid (unclotted) blood within the ventricles produces echoes; consequently these two types of haemorrhage cannot be separated reliably. A clue to liquid blood in the ventricles during the acute phase of periventricular haemorrhage may lie in degrees of asymmetry between the lateral ventricles due to anechoic liquid blood distending one or other ventricle as is shown in their figure $1 \mathrm{~b}$. This they claim to be subependymal haemorrhage (presumably unruptured), but I suggest it is as likely to be intraventricular haemorrhage.

Leaving aside the problem of diagnosis, intraventricular haemorrhage is a common condition, of major importance only if it is associated with subsequent handicap. Parenchymal extension ${ }^{4}$ and posthaemorrhagic ventricular dilation ${ }^{5}$ have both been suggested to be the most important factors predisposing to adverse outcome, but no infant in this study was reported to have had either of these complications, and therefore the question of whether vitamin $\mathrm{E}$ prevents major haemorrhage and possible handicap remains unanswered. In addition, there is evidence from Hittner et $a l^{6}$ that intraventricular haemorrhage was actually more common in infants receiving vitamin $\mathrm{E}$ supplements. In a double blind clinical study of the efficacy of large dose oral vitamin E.given early to very low birthweight babies to prevent retrolental fibroplasia more infants in the treatment group developed intraventricular haemorrhage, and, more specifically, twice as many infants sustained intraparenchymal haemorrhage in the vitamin $\mathrm{E}$ group than in the controls.

I understand that the Manchester group now intend to conduct a larger controlled study, and we must await further results before accepting that there is a protective effect of vitamin $E$ against intraventricular haemorrhage.

\section{I LeVENE}

Department of Child Health, Leicester Royal Infirmary,
Leicester LE2 7LX

Donn SM, Roloff DW, Goldstein GW. Prevention of intraventricular haemorrhage in preterm infants ii:215-7.

Morgan MEI, Benson JWT, Cooke RWI. Ethamsylate reduces the incidence of periventricular haemorrhage in very-low birth weight babies. Lancet 1981 ; ii : 830-1

Ment LR, Stewart WB, Scott DT, Duncan CC Beagle puppy model of intraventricular haemo Neurology $1983 ; 33: 179-84$

4 Thorburn RJ, Lipscomb AP, Stewart AL, et al. Prediction of death and major handicap in very preterm infants by brain ultrasound. Lancet 1981 ;ii: $1119-21$

Palmer P, Dubowitz LMS, Levene MI, et al. Development and neurological progress of preterm infants with intraventricular haemorrhage and ventricul dilatation. Arch Dis Child 1982;57:747-53.

ittner HM, Godio LB, Rudolph AJ, et al. Retrolental fibroplasia: efficacy of vitamin E in a double$1981 ; 305: 1365-71$.

SIR,-At first glance the findings of $\mathrm{Dr}$ Malcolm L Chiswick and others seem surprising, in that high dosage of vitamin E may be associated with impaired primary haemostasis for two reasons. Firstly, it has been shown to reduce the ability of normal adult platelets to aggregate. ${ }^{1}$ It was estimated that at a plasma concentration of about $70 \mu \mathrm{mol} / 1$ $(3 \mathrm{mg} / 100 \mathrm{ml}$ ), in practice the highest concentration achievable by oral supplementation and yet lower than the peak concentrations found in some of the parenterally treated babies, collagen induced aggregation would be reduced by up to half. Secondly, it has been observed that neonatal plasma has a reduced capacity to generate prostacyclin $\left(\mathrm{PGI}_{2}\right)$ in vitro, and that exogenous vitamin $\mathrm{E}$, albeit at a concentration five times that found in the plasma of the Manchester babies, would restore $\mathrm{PGI}_{2}$ generation to normal adult concentrations. ${ }^{2}$ In a healthy adult volunteer we have recently shown that after three days of ingesting DL- $\alpha$-tocopheryl acetate, $20 \mathrm{mg} / \mathrm{kg}$ body weight per day, the urinary excretion of 6-keto $\mathrm{PGF}_{1} \alpha$, a stable degradation product of $\mathrm{PGI}_{2}$, was increased from a mean of 96.2 (SE 4.42) fmol/mol creatinine to 169.5 (SE 26.3) fmol/mol creatinine $(p<0.02)$. Although confirmation is required in other subjects, this result suggests that vitamin $E$ at these pharmacological dosages may promote $\mathrm{PGI}_{2}$ production in vivo.

In the light of this it would be premature to assume that the very wide safety margin of vitamin $\mathrm{E}$ administration in older subjects holds true in the perinatal period. It is, therefore, important to document the occurrence of theoretical complications such as patent ductus arteriosus or pathological bleeding in babies thus treated. We would be interested to learn if such problems were encountered in the Manchester study.

\section{Department of Nephrology,}

The Children's Hospital,

C M TAYLOR

Department of Physiology,

Medical School

' Steiner M, Anastasi J. Vitamin E. An inhibitor of the platelet release reaction. $\mathcal{F}$ Clin Invest 1976;57:732-7. Stuart MJ. Deficiency of plasma $\mathrm{PGI}_{2}$-like regenerating activity in neonatal plasma. Reversal b
vitamin E in vitro. Pediatr Res $1981 ; 15: 971-3$.

**We sent a copy of these letters to the authors, who reply below.-ED, $B M \mathcal{H}$.

SIR,-We agree with Dr Levene that the absence of echoes from within the ventricles does not exclude the presence therein of liquid blood. Although ventricular asymmetry may be observed in the acute phase of intraventricular haemorrhage we do not feel it is specific for that condition. Our criteria for the diagnosis of subependymal and intraventricular haemorrhage are similar to those of other investigators who use the designation of "grade 1" to denote subependymal haemorrhage and grades 2-4 for intraventricular haemorrhage manifest as echogenecity within the ventricles. We chose for simplicity to lump together grades 2,3 , and 4 . In the control group four of the nine babies who suffered intraventricular haemorrhage had non-progressive ventricular dilatation (grade $3 ; \mathrm{n}=2$ ) or extension of the haemorrhage from the ventricles into the brain parenchyma (grade 4; $\mathrm{n}=2$; both died). In the babies receiving vitamin $E$ supplements one of the three with intraventricular haemorrhage had non-progressive ventricular dilatation (grade 3 ).

The preliminary results of our study must not be dismissed on the basis of comparisons with other investigations where vitamin $\mathrm{E}$ was given to premature babies to prevent retrolental fibroplasia and where the mortality or the prevalence of intraventricular haemorrhage was reported. Important variables include the 